\title{
DECONSTRUCTING THE CONSTITUENCY OF THE PUBLIC REASON Taking Systematic Conspiracy Theorists out of the Legitimation Pool
}

ADELIN-COSTIN DUMITRU, National University of Political Science and Public Administration, Bucharest, Romania

DUMITRU, A-C.: Deconstructing the Constituency of the Public Reason. Taking Systematic Conspiracy Theorists out of the Legitimation Pool FILOZOFIA, 75, 2020, No 4, pp. $263-278$

In the present article I argue that there is a class of conspiracy theorists that pose a threat to liberal democratic regimes, who tend to subscribe to potentially harmful conspiracy theories and can be regarded as unreasonable in two ways: i) do not accept the burdens of judgment; ii) are not motivated by a sense of justice. If we endorse political liberalism, we ought to partially exclude these citizens from the legitimation pool. The qualifier "partially" is important here, as I only endorse their exclusion qua bearers of an unreasonable conception. To the extent that they can employ other arguments, they will continue to be a part of the legitimation pool. Towards the end of the paper I investigate a potential counterargument to my position, which could be addressed by someone who postulates a Waldronian right to do wrong. I show that Quong's distinction between a right to do wrong and a non-right to be unreasonable can be extended in this instance and thus invalidate this potential criticism.

Keywords: Burdens of judgment - Conspiracy theorists - Legitimation pool Right to do wrong

\section{Introduction}

Conspiracy theories have always been with us in one form or another. Today, when the Internet has opened a whole new venue for "conspiracy entrepreneurs" (Sunstein and Vermeule 2009, 212), these are perhaps more prevalent than ever. As Levy has recently argued, conspiracies themselves are so ubiquitous "that refusing to believe in their existence would leave us unable to understand the contours of our world" (Levy 2007, 181). As such, it has become increasingly more important to analyze conspiracy theories in a critical way, without "treating them as simply a footnote to a long line of liberal anxieties about popular ignorance" (Moore 2016, 20). As I argue in this paper, 
what should really concern us is neither the truth value of conspiracy theories, nor the "crippled epistemology" that stands behind their existence (Hardin 2002, 16), but the fact that those who embrace them may not be reasonable citizens. As such, they should be excluded from the "legitimation pool", the constituency of people who must endorse a political conception according to political liberalism (Friedman 2004, 163), when they resort to arguments stemming from a harmful conspiracy theory. Although this might seem at first glance like a dark turn to the Rawlsian liberal project, I will show why the practical implications would not be radical. In fact, it would not be an exclusion of persons, but an exclusion of certain positions held by certain persons at times; what this proposal would lead to would be a system in which conspiracy theorists would be required to resort to other arguments, ones that belong to the realm of public reason.

According to Quong, unreasonable citizens are those who reject at least one of the following tenets of political liberalism: that political society is a fair system of social cooperation for mutual benefit, that all citizens should be conceived as free and equal and reasonable pluralism is a feature of society that should be cherished not decried $(2004,315)$. In turn, reasonable pluralism is closely intertwined with accepting the "burdens of judgment" and with embracing "their consequences for the use of public reason in directing the legitimate exercise of political power in a constitutional regime" (Rawls 1996, 54). The burdens of judgment are those that give birth to reasonable disagreement in a political community. Acknowledging them is to recognize the existence of "the many hazards involved in the correct and conscientious exercise of our powers of reason and judgment in the ordinary course of political life" (Rawls 1996, 56). The failure to be reasonable is reflected by the fact that some conspiracy theorists lack a sense of justice and thus "fail to recognize the independent validity of the claims of others" (Rawls 1996, 52). To the extent that some conspiracy theorists operate with the assumption that behind mundane and apparently unrelated events there is a cabal that pursues its "invariably nefarious" interests (Keeley 1999, 117), ${ }^{1}$ they do not accept the burdens of judgment and therefore should not be included in the legitimation pool.

In order to reach this conclusion I will proceed as follows. In the first section I explain what conspiracy theories are and how we should conceptualize them. I also try to show that not all conspiracy theories are created equal and that some might be more detrimental to society than others. In the second section I briefly present Rawlsian political liberalism and show why certain conspiracy theorists do not qualify

\footnotetext{
${ }^{1}$ Basham argues that although "there is no contradiction in the phrase conspiracies of goodness, these deceptions and manipulations are usually thought to express nefarious, even insanely evil purposes" $(2006,61)$.
} 
as reasonable citizens. In the third section I provide an analysis of a study case about the conspiracy emerged in the winter of 2017 regarding George Soros' purported involvement in the Romanian street protests against Ordinance 13. The last section concludes the paper and addresses an important potential criticism.

In order to avoid including too mисh in the class of potentially harmful conspiracy theorists, I refer only to what may be called systematic conspiracy theorists, i.e. those who are either inclined to believe a large number of such theories and who dismiss any evidence contrary to their beliefs. I add the first qualifier due to Radnitz and Underwood's research, which showed that "the vast majority of citizens may be potential conspiracy theorists" under the "right" circumstances; according to this interpretation, individuals adhere to such narratives as an attempt to reduce uncertainty when faced with unexplained events $(2015,114)$. The second qualifier is meant to exclude those conspiracy theorists who are innocuous. (Sunstein proceeds in a similar way when he distinguishes "potentially harmful conspiracy theories" from "not harmful theories" $(2016,20)$. The main difference is that my attention is on the persons who employ such theories, and not necessarily on the theories themselves. In the following section I present a criterion that could be employed between distinguishing the two.

\section{Identifying the potentially harmful conspiracy theories}

As mentioned, not all conspiracy theories are created equal. Some of these are innocuous for democracy, while others might be detrimental to the values upon which this political regime is founded. In fact, there are authors who claim that most conspiracy theories are related to each other only through a (Wittgensteinian) family-resemblance structure (Sunstein and Vermeule 2009, 205). Before I attempt to provide a criterion for separating these two kinds of conspiracy theories, perhaps it would be useful to see how we may define them and how they have been defined in the literature so far.

Popper was the one who brought to the fore academic interest in the problem of conspiracies. He criticized those who upheld "the conspiracy theory of society", i.e. those who "believe that institutions can be understood completely as the result of conscious design... as conspiring agents, just as if they were individual men" (2006 [1972], 15). What Popper objected to first and foremost was an ontological mistake committed by such individuals; close behind it was an epistemological mistake, that of disregarding the "unwanted consequences" of human action (2006 [1972], 14). ${ }^{2}$ The propensity to believe in a cabal that tries and succeeds in reaching its (nefarious)

\footnotetext{
${ }^{2}$ For criticism of Popper see Pigden (2006).
} 
goals is a characteristic emphasized invariably in the literature. Keeley calls conspiracy theorists "the last believers in an ordered universe" (1999, 123 - 124), in a manner akin to the way religious believers find purpose anywhere. ${ }^{3}$ Other authors, such as Hayek, propose that conspiracy theorists conceive the world as a Newtonian mechanical order and disregard the possibility that social arrangements might be the product of spontaneous order (Hayek 2006 [1944], 15) or of unintended consequences. As Moore puts it, "by invoking the idea that some hidden group of people is directing events, conspiracy theorists avoid confronting a world in which there is typically not a strong correspondence between outcomes and the intentions of any of the people whose interaction produced them" $(2016,4)$. In a similar vein, Sunstein and Vermeule define conspiracy theories as attempts to explain events or practice "by reference to the machinations of powerful people, who attempt to conceal their role" $(2009,205)$. This is doubled by a typical "overestimation of the competence and discretions of officials and bureaucrats, who are assumed to be capable of devising and carrying out sophisticated secret plans" (Sunstein 2016, 21). Keeley holds that for a conspiracy theory it is not a necessary condition to assume that conspirators are all powerful, only that "they have played some pivotal role in bringing about the event" $(1999,116)$. Oliver and Wood identify 3 common characteristics of conspiracy theories: proposing a causal relation between "unusual" social and political phenomena and "unseen, intentional and malevolent forces"; conceiving political events in Manichean terms and suggesting that official account are attempts to "distract the public from a hidden source of power" $(2014,953)$. Coady states that the nefarious motivation of the conspirators is not a necessary condition. Instead, "two things seem to be essential to a conspiracy: to involve a group of agents acting together, and to be secretive"; to this we might add the fact that all conspiracy theories are explanations "contrary to those that have official status at the time and place in question" $(2006,1-2)$.

We see that there are several recurring elements in all the mentioned definitions. Nonetheless, this does not get us very far for the purposes of this article, as the characteristics mentioned cannot be employed to distinguish between potentially harmful and innocuous conspiracy theories. We need to add a couple of more elements. Conspiracy theories, by themselves, are not necessarily harmful or innocuous. All conspiracy theories are either harmful or innocuous, depending on how they are used (although some conspiracy theories have intrinsic characteristics that make them more susceptible to be used in a potentially harmful way). However, if they are not employed by individuals, even those harmful conspiracy theories have no potency in dis-

\footnotetext{
${ }^{3}$ I thank an anonymous reviewer for this interpretation.
} 
rupting the public reason. This is why we should focus more on the behavior of conspiracy theorists and less on the characteristics of conspiracy theories (albeit I will propose later on a criterion through which we can distinguish between potentially harmful or innocuous theories; the qualifier "potentially" is important here, since, as mentioned beforehand, they can best be classified as such only if and after someone employs them).

First of all, we must distinguish between those who are incidentally conspiracy theorists and those who make a lifestyle out of it. It seems a qualitative difference between those who "interactively deconstruct official versions of the truth, consume alternative accounts and produce their own constructed theories on forums, websites, or Youtube" (Harambam and Aupers 2014, 5 -6) and those who happen to believe for a brief period in a conspiracy theory due to circumstances. Although at first glance this might seem a distinction between producers and consumers of such theories, ${ }^{4}$ the real distinction is between those who actively promote such theories and reject communication with others, and people who simply believe them, but still engage in political debate, and do not try to convince others. As such, some consumers might turn out to be problematic from the standpoint of political liberalism. This is because, as Radnitz and Underwood show in their study, "conspiracy belief need not signal a categorical rejection of political engagement, but may be situational and compartmentalized from other beliefs" $(2015,114)$. If the "right" circumstances occur, then most individuals would lean towards such narratives. Oliver and Wood argue that when people are inclined "to make causal attributions of salient phenomena to unseen forces", they are more likely to believe such narratives $(2014,954)$. This might happen whenever people are anxious, since "invocation of a conspiracy restores a sense of certainty" (Radnitz and Underwood, 123).

Furthermore, we need to distinguish between those individuals who would easily renounce at conspiracy narratives should empirical proof against these arise, and those who are impervious to the falsification of their theory (it could be argued that only the latter are proper conspiracy theorists, as they believe that all the "purported proofs" against their theory is in fact a proof that there is a conspiracy, and that the cabal is trying to hide this: see Keeley 1999). I shall call systematic conspiracy theorists those individuals who believe that social or political events are caused by a malevolent cabal, who dismiss any evidence against their beliefs and who display a propensity to either believe a large number of conspiracy theories or to be very attached to a particular conspiracy theory. Furthermore, these individuals actively promote their theories, and try to convince other people to embrace their beliefs. As Sunstein and Vermeule

${ }^{4}$ I thank an anonymous reviewer for this objection. 
mention, borrowing Hardin's concept of "crippled epistemology" (2002), conspiracy theorists "know very few things, and what they know is wrong". As such, they resemble extremists, in that what they know "stems not form irrationality, but from the fact that they have little relevant information" $(2009,214)$, and act as if what they believed were true, without trying to update their information or to accept opposite viewpoints. Furthermore, they are susceptible to phenomena such as informational cascades or group polarization ${ }^{5}$, which harden their positions after deliberation with similarly minded individuals $(2009,215-216)$. On a related note, Levy mentions that the person who subscribes to a conspiracy theory "risks [...] epistemically disabling herself" $(2007,181)$. Similarly, Clarke believes that conspiracy theorists are "victims of a form of cognitive failure", in that "they are unusually prone to committing what social psychologists refer to as the fundamental attribution error" $(2002,133)$. This means that they emphasize too much dispositional explanations (those which refer to character traits or psychological characteristics of the agents) and downplay the importance of situational explanations (Coady 2006, 8). Clarke identifies a similarity between Lakatosian degenerating programs and conspiracy theories. Auxiliary hypotheses are proposed in both in order to insulate the theory from invalidation (Clarke 2002, 136). A degenerating program is, according to Lakatos, one in which its "theoretical growth lags behind its empirical growth", and which increasingly resorts to "post hoc explanations" (Lakatos 1978, 112). As Clarke makes clear, Lakatos does not provide criteria for saying "when it becomes irrational to cling to a degenerating research program", but he believes that there are certain cases in which constant evidence against a theory would disqualify one from being rational if he clings to that theory $(2002,136)$.

This is why the conspiracy theorists I am concerned with in this article-systematic conspiracy theorists - differ from other kinds of individuals who might be interested in a conspiracy theory. ${ }^{6}$ For instance, Pigden mentions that it would sometimes be irrational not to investigate conspiracy theories (if the evidence shows that they might be true, as in the case of the Watergate scandal, which began as a conspiracy theory $(2007,226)$. What investigative journalists do, however, is to update the information they believe. Furthermore, they do not reject all information they receive. They are interested in pursuing the truth. Although sometimes what they find out might decrease trust, they are basing their conclusions on warranted information, and as such they cannot be classified as systematic conspiracy theorists.

How to distinguish between potentially harmful and potentially innocuous conspiracy theories? I propose the following criterion. If a conspiracy theory can "tear

\footnotetext{
${ }^{5}$ For the concept of group polarization see also Sunstein (2001).

${ }^{6} \mathrm{I}$ thank an anonymous reviewer for raising this issue.
} 
a hole in the web of distributed knowledge, placing at risk not merely the social relations of testimony and trust, but also the very resources of knowledge acquisition" (Levy 2007, 190), then we face a potentially harmful conspiracy theory. This happens when one actively seeks the company of other similarly minded people, increasingly giving up on being embedded in an open society and preferring a closed, "epistemically-disabling" community (for the term see Levy 2007, 181). This is more likely to happen in the case of systematic conspiracy theorists, since occasional conspiracy theorists turn towards such narratives "when there are no overt political appeals to shape opinion... then, people rely on cognitive heuristics that link the information in question to relevant associations and identities" (Radnitz and Underwood 2015, 115). By contrast, systematic conspiracy theorists refute $a$ priori official narratives and all subsequent proofs against their theories. Such closed communities are dangerous for democracy; such potentially harmful doctrines may need to be "contained" (this is the term used by Rawls 1996, 64 n 19). As several authors emphasized, such conspiracy theories resemble Lakatosian "degenerating research programs, in which contrary evidence is explained away by adding epicycles and resisting falsification of key tenets" (Sunstein and Vermeule 2009, 221; see also Clarke 2002, 136 - 137). For instance, to believe that the Government hides proof in extra-terrestrial life is an innocuous conspiracy theory (it is a conspiracy theory as it is unwarranted, i.e. there is no reason to believe in it and as such it is unjustifiable, even if it might be true; for the distinction between truth and justification see Keeley 1999, 111 and Sunstein and Vermeule 2009, 207). By contrast, to believe that your fellow citizens are extra-terrestrials in disguise is a potentially harmful doctrine, as it might lead to rejecting engaging in social relations with them. It is important to understand exactly what is the difference between the 2 conspiracy theories. The former respects all the formal criteria that make it a conspiracy theory. However, it has not impact on how people relate to one another. Should the citizens holding it start believing other related conspiracy theories (Such as the second one mentioned), this is where problems would start for political liberalism. The point is that, by themselves, theories do not say much. Any conspiracy theory can, in fact, be potentially harmful or potentially innocuous. Much more hinges on how conspiracy theorists employ them. Whenever the key precepts of a conspiracy theory preclude someone from taking seriously the claims and conceptions of the good of other citizens, we can say that he holds a harmful conspiracy theory.

\section{Systematic conspiracy theorists as unreasonable citizens}

In this section I will present the key tenets of political liberalism and I will argue that systematic conspiracy theorists are unreasonable citizens and thus should be partially excluded from the legitimation pool (for clarification, they should be excluded to the 
extent that they endorse an unreasonable doctrine ${ }^{7}$ ). I do not intend to provide a complete overview of political liberalism and I am not concerned with the immense literature that has been written on public reason (for that, see Quong 2013).

According to Rawls, political liberalism aims at finding an adequate answer to the question of how is it possible to have a just and stable society given the fact of reasonable pluralism, i.e. the existence of "conflicting and even incommensurable religious, philosophical and moral doctrines" (Rawls 1996, 133). Furthermore, we must seek stability for the right reasons, which shows that citizens do not merely tolerate each other as in a modus vivendi characterized by a balance of forces, but in which they are motivated by a sense of justice "that inclines them not only to accept but to act upon the principles of justice" (Rawls 1999, 45). Rawls' answer is that we must identify a political conception that can become an overlapping consensus of a plurality of reasonable comprehensive doctrines (Rawls 1996, XIX). Political liberalism thus attempts to show that, under conditions of reasonable pluralism, a well-ordered and stable democratic government is possible (Rawls 1996, XXXIX). For that to be feasible, Rawls argues that we need a freestanding political conception of justice, one that is independent from the tenets of one or another comprehensive doctrine (Rawls 1996, XLII). A political conception can take various forms, depending on how it specifies 3 main features that any such conception must display: 1) a specification of certain basic rights and liberties; 2 ) a specification of the priority of the right over the good; 3 ) a specification of measures assuring that all citizens have adequate all purpose means to make use of those rights and liberties and opportunities (Rawls 1996, 6). For instance, under Rawls' justice as fairness, the third element is operationalized in the form of primary goods, which are conceived as "all-purpose means that are generally necessary to enable citizens adequately to develop and fully exercise their two moral powers, and to pursue their determinate conceptions of the good" (Rawls 2001, 57). Other political conceptions might operationalize such all-purpose means differently. All political conceptions: 1) apply to the basic structure; 2) are presented as freestanding views ("essential constituent parts, that fit into and can be supported by various reasonable comprehensive doctrines" and 3) express certain fundamental ideas in a democratic society such as the necessity of human rights (Rawls 1996, $12-13$ ).

In order for a society to function according to the principles of a political conceptions, Rawls argue that we must conceive the citizens as being free and equal persons, endowed with two distinct moral powers: a capacity for a sense of justice and a capacity for a conception of the good (Rawls 1996, 19). The first moral power

\footnotetext{
${ }^{7}$ I thank an anonymous reviewer for this clarification.
} 
is given by the fact that citizens are reasonable; the second is a consequence of citizens being rational. Rationality means that "an individual is endowed with the powers of judgment and deliberation in seeking ends and interests" and "applies to the choice of means, in which case it is guided by principles such as adopting the most effective means to ends or to select the more probable alternative" (Rawls 1996, 50). On the other hand, to be reasonable means to be "ready to propose principles and standards as fair terms of cooperation and to abide by them willingly, given the assurance that others will likewise do so" (Rawls 1996, 49). The reasonable is "public", which means that "by the reasonable we enter as equals the public world of others and stand ready to propose, or to accept fair terms of cooperation with them" (1996, 53). Reasonability means that you are willing to propose fair terms of cooperation and to recognize the burdens of judgment and "to accept their consequences for the use of public reason in directing the legitimate exercise of political power in a constitutional regime" $(1996,54)$.

What means that the exercise of power is legitimate? In constitutional regimes, even if the political power ultimately resides in citizens, its exercise is always coercive ("backed by the government's use of sanctions", as Rawls puts it 1996, 136). Rawls proposes the following liberal principle of legitimacy: "our exercise of political power is proper only when it is exercised in accordance with a constitution the essentials of which all citizens as free and equal may reasonably be expected to endorse in the light of principles and ideals acceptable to their common human reason" $(1996,137)$. In order to avoid the clash of divergent comprehensive doctrines, citizens must settle issues regarding "questions about basic justice and constitutional essentials" by appealing to political values alone $(1996,138)$. Rawls calls this a "duty of civility" $(2001,117)$ and adds that it requires us to justify public policies and legislation ultimately through political values, even if in the first instance we might find reasons for them in our comprehensive doctrines (2001, 90; this is the so-called "proviso"). Citizens ought to settle matters regarding basic justice and constitutional essentials ("what religions are to be tolerated, who is to be assured fair equality of opportunity, who has the right to vote") by appealing to the norms of public reason (Rawls 1996, 213 214). The ideal of public reason holds for citizens whenever "they engage in political advocacy forums, in advocacy of political parties, for candidates in their campaigns, for judges" $(1996,215)$.

As Quong argues, unreasonable citizens reject the very premises of political liberalism exposed above. As such, their unreasonable views "are simply of no normative interest in the process of political justification" $(2004,315)$. This does not mean that the benefits of citizenship are not protected or that their rights are violated, "only that they are not part of the constituency of public justification that determines what 
those rights and benefits will be" $(2004,315)$. Thus, they are not part of the legitimation pool (Friedman 2004, 163). Political decisions and public policies must not gain their endorsement, as the liberal principle of legitimacy requires in the case of reasonable citizens. Now that we have the basics of political liberalism, should conspiracy theorists be excluded from the legitimation pool? In order to respond affirmatively to this question, we must first show that they are unreasonable and that they lack a sense of justice.

There are two ways in which systematic conspiracy theorists can be understood as unreasonable. One has to do with their rejection of the burdens of judgment and the other with their repudiation of the validity of other citizens' claims. Let me begin with the burdens of judgment argument. For Rawls, the burdens of judgment are the sources of disagreement between reasonable persons, the "many hazards involved in the correct and conscientious exercise of our powers of reason and judgment in the ordinary course of political life" (Rawls 1996, 55 - 56). The burdens of judgment offered by Rawls are the following: the evidence bearing on cases is conflicting and complex, aspects which make it difficult to assess and evaluate these cases; even when we are in full agreement over what considerations are relevant, we might be in disagreement concerning their weight; all concepts are to some extent "vague and subject to hard cases; and this indeterminacy means that we must rely on judgment and interpretation"; the way we assess "evidence and weigh moral and political values is shaped by our total experience" and the existence of "different kinds of normative considerations of different force on both sides of an issue, making it difficult to make an overall assessment" (Rawls 1996, 56 - 57). On the other hand, for systematic conspiracy theorists, things are either black or white: the political officials try to hide the truth behind their actions, and have perfect control over these actions. They are unwilling to accept that people might commit errors and that undesirable results might be unintended consequences and not conscious products of human action. In general terms, systematic conspiracy theorists do not give those that they regard as being part of a cabal the benefit of the doubt ${ }^{8}$. However, this might not warrant excluding them from the legitimation pool. It is when systematic conspiracy theorists reject the possibility of dialogue with others, as a consequence of not believing that they are wellintentioned, that problems arise. Oftentimes, this is often associated with the second, related, problem of systematic conspiracy theorists, their rejection of the validity of other citizens' claims.

\footnotetext{
${ }^{8}$ I thank Oana Derviș for this formulation.
} 
Keeley mentions that "to the extent that conspiracy theory relies on a global and far-reaching doubt of the motives and good will of others, it is akin to global philosophical skepticism" $(1999,126)$. This means that systematic conspiracy theorists lack what Rawls calls "a reasonable moral psychology", i.e. "the capacity to acquire conceptions of justice and fairness and a desire to act as these conceptions require. When they believe that institutions or social practices are just, or fair, they are ready and willing to do their part in those arrangements provided they have reasonable assurance that others will also do their part" (Rawls 1996, 86). In closed, faux-democratic regimes, conspiracy theorists might be onto something. They might be entitled to express distrust in the authorities and in the official narratives. However, in liberal democracies, though these depart to a degree from Rawlsian well-ordered societies, they lack the reasons for completely lacking trust that others would be ready and willing to do their part in political arrangements. They reject the fact of reasonable pluralism, as they do not believe that the conceptions of the good of other citizens are their own. They believe that their fellow citizens are manipulated by some cabal or that they have some hidden interests they pursue. They are not willing to accept the fact that other people might hold different conceptions of the good, and as such they reject reasonable pluralism, the very premise of political liberalism. Remember that I do not talk about all conspiracy theorists, but only about a subset of systematic conspiracy theorist. Furthermore, I am preoccupied with potentially harmful conspiracy theories, which represent instances of unreasonable comprehensive doctrines. However, even if we agree that we should exclude systematic conspiracy theorists from the legitimation pool, should we contain them?

Rawls has not discussed at length the issue of containing unreasonable doctrines. He briefly mentions that, as these "reject one or more democratic freedoms, we must contain them - like war and disease" (1996, 64 n 19). It is Quong who developed upon the Rawlsian framework and clarified what the containment of such doctrines means. The justification for containing unreasonable doctrines stems from the importance of normative stability in a liberal democracy (Quong 2004, 324). Following Rawls, he defines normative stability as the ability of a democratic regime to "generate its own support in a suitable way by addressing each citizens' reason, as explained within its own framework" (Rawls 2001, 186, apud Quong 2004, 324). Thus, doctrines "which deny the freedom and equality of persons must not become so prevalent that they threaten to undermine the essentials of a liberal democratic regime" $(2004,324)$. However, Quong says that the burden of proof is always on those who try to stifle comprehensive doctrines, be these apparently unreasonable: "the practical application of the containment argument should always be tempered by a strong presumption in favour of non-interference" (Quong 2004, 329). I believe that potentially harmful conspiracy 
theories should be contained in a soft way: the cognitive infiltration strategy mentioned by Sunstein and Vermeule might be a good starting place. They hypothesize that cognitive infiltration "designed to break up the crippled epistemology of conspiracy-minded groups and informationally isolated social networks" could be effective against conspiracy theories $(2009,227)$. The specific way in which this should be accomplished, however, is outside the scope of this paper. In the next section I will present a case which shows why systematic conspiracy theorists endorsing harmful narratives should be excluded from the legitimation pool.

\section{Ordinance $13 / 2017$ and the Soros conspiracy in Romania}

In the winter of 2017, the Romanian government passed an emergency ordinance that concerned changes to the Criminal Code. Ordinance 13/2017 would have decriminalised official misconduct in cases where the financial damage did not reach the threshold of 200,000 RON (the equivalent of roughly $\$ 49,000$ ). The ordinance, passed by the Social Democratic Party, which won the elections in December 2016, attracted widespread national and international criticism, since it was felt that it would reverse the fight against corruption (one of the articles stipulated the release of several former politicians arrested in the previous years). ${ }^{9}$ More than half a million Romanians protested in the streets against the Ordinance, most of them in $\mathrm{Bu}$ charest, but also in other large cities such as Timișoara or Sibiu. ${ }^{10}$ Over the next month, the society became divided in two: those endorsing the government and those opposing it, asking for the resignation of the officials who promulgated the Ordinance. Speculation about the legality of the Ordinance, about what would happen with it if the government were to resign, abounded during that month. Retired generals announced on television that state authorities could legitimately use ammunition against the citizens protesting in the streets. ${ }^{11}$

At the end of February, the Chamber of Deputies voted for a law that effectively annulled Ordinance 13, and approved the Government's Emergency Ordinance 14 , which was previously promulgated by the government in order to repeal Ordinance $13 .{ }^{12}$ We need not explore the case in more details. This brief sketch suffices for the purposes of the paper. What is more important is the fact that on the

\footnotetext{
${ }^{9} \mathrm{https} / / /$ www.theguardian.com/world/2017/feb/01/romanians-protests-emergency-law-prisonerpardons-corruption , last accessed on April 10th, 2020.

${ }^{10} \mathrm{https}: / / \mathrm{www}$. theguardian.com/world/2017/feb/06/27-years-of-corruption-is-enough-romanianson-why-theyre-protesting, last accessed on April 10th, 2020.

${ }^{11} \mathrm{http} / / /$ romanialibera.ro/actualitate/eveniment/pavel-abraham--la-romaniatv---organele-potfolosi----in-mod-democratic----munitie-impotriva-manifestantilor----foto-439630, last accessed on April 11th, 2020.

12 https://www.romania-insider.com/protests-romania-reach-goal-emergency-ordinance-justiceofficially-terminated/, last accessed on April 11th, 2020.
} 
Internet and on televisions emerged a different narrative: that billionaire George Soros was secretly funding the protests. 3 important television posts received fines for spreading fake news. ${ }^{13}$ Soros was accused of orchestrating the protests and paying the people who were chanting in the streets anti-governmental messages. On the channel România TV, an anchor announced the public that Soros paid 100 lei for each adult, 50 lei for each child and 30 lei for each $d o g$ that was in the street. ${ }^{14}$ Leaving aside the ridicule of the situation, many other televisions made similar announcements, qualifying the protests as a coup d'etat attempt. Soros was believed to be behind this conspiracy, slowly but steadily realizing his objectives of destabilizing Romania and overturning the democratically elected government. It was not the first time Soros was announced as the driving force behind civil movements in Romania, and it was not the last time. In the spring of 2017, the Romanian Parliament approved a petition signed by over 3 million Romanians (the so-called Coalition for the Family) for a referendum asking for a Constitution amendment that would explicitly state that a family is formed by a man and a woman, effectively blocking any chance of legalizing LGBTQI+ marriages in Romania. The civil society's response was swift, and an online platform was recently set up by nongovernmental organizations in order to endorse LGBTQI+ rights and other human rights that might be imperilled by the Coalition for the Family. ${ }^{15}$ Soros was once again announced by proponents of the Coalition for the Family as standing behind this initiative.

In Romania, the name of George Soros has become associated with illiberal conspiracy theorists who disregard the conceptions of the good of their fellow citizens by assuming that they are paid by a billionaire. As such, the conspiracy around George Soros can be regarded as potentially harmful, as it motivates a movement that would effectively tamper with constitutional essentials and matters of basic justice. The claim of this paper is that such systematic conspiracy theorists should be excluded from the legitimation pool to the extent that they employ arguments stemming from such harmful conceptions. By rejecting reasonable pluralism, by not acknowledging the burdens of judgment and by engaging in a conspiracy that is meant to disqualify any liberal reaction to their comprehensive doctrines, these systematic conspiracy theorists violate the norms of public reason. What disqualifies them is the fact that they endorse potentially harmful conspiracy theories. Should they put forth arguments that can be justified otherwise, this exclusion would cease to be applicable.

\footnotetext{
${ }^{13} \mathrm{http} / / / \mathrm{www} . z i a r e . c o m / m e d i a / c n a / t e l e v i z i u n i-a m e n d a t e-d e-c n a-d u p a-c e-a u-s p u s-c a-s o r o s-$ controleaza-tot-in-romania-sesizarile-pe-proteste-mai-au-de-asteptat-1452037, last accessed on April 11th, 2020.

${ }^{14} \mathrm{http}$ ://romanialibera.ro/actualitate/eveniment/foto---video--manipulari-la-romania-tv--burtiereleau-transmis-ca-la-protestele-din-bucuresti-s-au-platit-30-de-lei-de-caine--50-de-lei-de-copil-si100-de-lei-de-adult-438914, last accessed on April 11th, 2020.

${ }^{15}$ https://platformarespect.ro/
} 


\section{Conclusions}

I argued in this paper that there is a certain class of conspiracy theories, what I called potentially harmful conspiracy theories, which pose a threat to liberal democracies, to the extent that they become part of the discursive strategy of systematic conspiracy theorists. Their proponents, the systematic conspiracy theorists, are unreasonable citizens and as such should be excluded from the legitimation pool. An objection that could be addressed to my account could be forged on the presumption that citizens have a right to do wrong (Waldron 1981). In this last part of the paper I shall address this potential criticism, starting from Quong, who argued that we must separate the right to do wrong from the right to be unreasonable (2004, 330 - 335).

Waldron justifies the right to do wrong by referencing the necessity of ensuring that individuals can make choices that are crucial to their personal integrity. The fact that those areas of choice that are vital for personal integrity are protected by rights does not entail that rights can direct individuals towards one course of action or another. Starting from this premise, Waldron asserts that we cannot exclude a priori the possibility that individuals might follow paths that are morally blameworthy. In his words, "each action protected by a right will, in its particular circumstances, be an action that is called for from the moral point of view, or an action that is subject to moral criticism, or an action on which morality has nothing of importance to say" (1981, 34 - 35). The rightness of an act is a distinct matter from the right to do an act. Although we may make a choice that is condemnable under the rightness lens, this does not necessarily mean that we should not have the right to do it (Waldron 1981, 37). Quong translates this as meaning that our choice set cannot be limited ab initio to options that are morally laudable: "if this were the case, then I would only have the right to choose between something demanded by morality and something not demanded by morality, which is effectively no choice at all" (Quong 2004, 331). Quong accepts the right to do wrong, but claims that there is no right to be unreasonable. Wrongness does not imply the violation of principles of justice (Quong 2004, 332). The principle of not interfering with the private beliefs of citizens ceases to be applicable whenever we deal with "significantly weighty public reasons" (Quong 2004, 333). Quong's conclusion is that unreasonable citizens cannot resort to a right to do wrong as a defence of their comprehensive doctrines, as we deal here with different conceptual categories.

By extension, the same argument applies in the case of systematic conspiracy theorists. Those conspiracy theorists who believe in innocuous narratives can take advantage of the right to do wrong, as its purpose is to protect their conceptions of the good, which are not incompatible with a political conception of justice. By contrast, 
I have shown that systematic conspiracy theorists and the harmful narratives they endorse can have a very detrimental impact on the liberal-democratic fundaments. Thus, they cannot defend their actions by resorting to the right to do wrong, as they reject the very fundamentals of the regime that specifies in the first place such a right (Quong 2004, 334). The case for taking systematic conspiracy theorists out of the legitimation pool thus cannot be invalidated by postulating a right to do wrong. Thus, the argument this paper makes is more moderate than it might have initially seemed. The "candidates" for exclusion from the legitimation pool are only those systematic conspiracy theorists who endorse some conspiracy theories that lead them to reject the burdens of judgment and not to be motivated by a sense of justice. Other conspiracy theories and their supporters can easily find a place in liberal democracies (for what kind of place they could have, see Dentith 2014).

\section{Bibliography}

BASHAM, L. (2006): Living with the conspiracy. In: Coady, D. (ed.): Conspiracy theories. The philosophical debate. Hampshire: Ashgate, 61 - 75.

CLARKE, S. (2002): Conspiracy theories and conspiracy theorizing. Philosophy of the Social Sciences, $32(2), 131-150$.

CLARKE, S. (2006): Appealing to the fundamental attribution error: was it all a big mistake? In: Coady, D. (ed.): Conspiracy theories. The philosophical debate. Hampshire: Ashgate, 129-133.

COADY, D. (2006): An introduction to the philosophical debate about conspiracy theories. In: Coady, D. (ed.): Conspiracy theories. The philosophical debate. Hampshire: Ashgate, 1 - 13.

COADY, D. (2007): Are conspiracy theorists irrational? Episteme 4, 193 - 204.

DENTITH, M. R. X. (2004): The philosophy of conspiracy theories, Hampshire: Palgrave Macmillan. FRIEDMAN, M. (2004): Autonomy, gender, politics. New York: Oxford University Press.

HARAMBAM, J., AUPERS, S. (2014): Contesting epistemic authority: conspiracy theories on the boundary of science. Public Understanding of Science, 24 (4), $1-15$.

HARDIN, R. (2002): The crippled epistemology of extremism. In: Breton, A. - Galeotti, G. Salmon, P. - Wintrobe, R. (eds.): Political Extremism and Rationality. Cambridge: Cambridge University Press, 3 - 22.

HAYEK, F. (2006): The road to serfdom. New York: Routledge.

KEELEY, B. (1999): Of conspiracy theories. The Journal of Philosophy, 96 (3), 109 - 126.

LAKATOS, I. (1978): The methodology of scientific research programs. In: Worrall, J. - Currie, G. (eds.). New York: Press Syndicate of the University of Cambridge.

LEVY, N. (2007): Radically socialized knowledge and conspiracy theories. Episteme, 4 (2), 181 - 192.

MOORE, A. (2016): Conspiracy and conspiracy theories in democratic politics. Critical Review, 28 (1), $1-23$.

OLIVER, E., WOOD, Th. (2014): Conspiracy theories and the paranoid style of mass opinion. American Journal of Political Science, 58 (4), 952 - 966.

PIGDEN, Ch. (2006): Popper revisited, or what is wrong with conspiracy theories? In: Coady, D. (ed.): Conspiracy theories. The philosophical debate. Hampshire: Ashgate, $17-45$.

PIGDEN, Ch. (2007). Conspiracy theories and the conventional wisdom. Episteme, 4, 219 - 232.

POPPER, K. (2006): The conspiracy theory of society. In: Coady, D. (ed.): Conspiracy theories. The philosophical debate. Hampshire: Ashgate, $13-17$. 
QUONG, J. (2004): The rights of unreasonable citizens. The Journal of Political Philosophy, 12 (3), $314-335$.

QUONG, J. (2013): Public reason. The Stanford Encyclopedia of Philosophy. [online]: https://plato.stanford.edu/entries/public-reason.

RADNITZ, S., UNDERWOOD, P. (2015): Is belief in conspiracy theories pathological? A survey experiment on the cognitive roots of extreme suspicion. British Journal of Political Science, $47,113-129$.

RAWLS, J. (1999): The law of peoples, with "The idea of public reason revisited". Cambridge: Harvard University Press.

RAWLS, J. (2001): Justice as fairness. A restatement. Cambridge: The Belknap Press of Harvard University Press.

RAWLS, J. (1996): Political liberalism. New York: Columbia University Press.

SUNSTEIN, C., VERMEULE, A. (2009): Conspiracy theories: causes and cures. The Journal of Political Philosophy, 17 (2), 202 - 227.

SUNSTEIN, C. (2001): Designing democracy. What constitutions do. New York: Oxford University Press.

SUNSTEIN, C. (2016): Conspiracy theories and other dangerous ideas. New York: Simon \& Schuster.

WALDRON, J. (1981): A right to do wrong. Ethics, 92 (1), 21 - 23, Faculty of Political Science, National.

Adelin-Costin Dumitru

National University of Political Science and Public Administration

Expoziției no.30A

Bucharest, zip code 012104

Romania

e-mail: adelin.dumitru1@gmail.com

ORCID ID: https://orcid.org/0000-0002-6127-1467 